\title{
Correlation of NEDD4-1 and PTEN expression with the invasive capacity of pituitary adenomas
}

\author{
$\mathrm{JING} \mathrm{ZHANG}^{1}, \mathrm{XIN} \mathrm{LI}^{2}$ and YANYAN ZHANG ${ }^{1}$ \\ ${ }^{1}$ Department of Neurosurgery, Heze Municipal Hospital, Heze, Shandong 274000; ${ }^{2}$ Department of Neurosurgery, \\ Liaocheng People's Hospital and Liaocheng Clinical School of Taishan Medical University, \\ Liaocheng, Shandong 252000, P.R. China
}

Received December 21, 2015; Accepted November 3, 2016

DOI: $10.3892 / \operatorname{mco} .2016 .1092$

\begin{abstract}
The aim of the present study was to correlate the expression of neural precursor cell expressed developmentally downregulated 4-1 (NEDD4-1) and phosphatase and tensin homolog deleted on chromosome 10 (PTEN) with the invasive capacity of pituitary adenomas. A total of 50 pituitary adenoma tissues and 10 normal pituitary tissues were divided into the invasive group (26 cases), the non-invasive group (24 cases) and the normal group (10 cases). The expression of NEDD4-1 and PTEN was determined by immunohistochemistry. NEDD4-1 was revealed to be located in the nucleus and cytoplasm, whereas PTEN was only located in the cytoplasm. Furthermore, expression of NEDD4-1 was higher in pituitary adenomas compared with normal pituitary tissues $(\mathrm{P}<0.05)$, and higher in the invasive group compared with the non-invasive group, whereas the opposite trend was observed for PTEN. There was a strong negative correlation between NEDD4-1 and PTEN expression, indicating a dependency between the two and an association with invasiveness. In conclusion, NEDD4-1 may serve as a diagnostic and prognostic factor, and as a novel therapeutic target, in pituitary adenomas.
\end{abstract}

\section{Introduction}

Pituitary adenoma is a common type of neurological neoplasm and the third most common type of intracranial tumors. While pituitary adenomas are classified as benign tumors, a proportion of them exhibit invasive growth towards the surrounding normal structures, including the skull, cavernous sinus, dura, sphenoid bone, the third ventricle, and even the pharyngonasal cavity (1). Although recent studies

Correspondence to: Dr Jing Zhang, Department of Neurosurgery, Heze Municipal Hospital, 2888 Caozhou Road, Heze, Shandong 274000, P.R. China

E-mail: zj4693250@126.com

Key words: invasion, neural precursor cells, developmentally downregulated 4-1, phosphatase and tensin homolog deleted on chromosome 10 , pituitary adenomas, immunohistochemistry have advanced the current knowledge on the pathogenesis of pituitary adenoma, the precise mechanisms and causes have remained elusive. Phosphatase and tensin homolog deleted on chromosome 10 (PTEN), the first known tumor suppressor gene with phosphatase activity, was first cloned and named in 1997 (2,3). In 2007, neural precursor cell expressed developmentally down regulated 4-1 (NEDD4-1) was identified by Wang et al (4). NEDD4-1 has an important role in downregulating the levels of PTEN. It can promote the degradation of PTEN in the proteasome by adding a molecular marker, ubiquitin (4-8). To the best of our knowledge, no previous studies have assessed whether NEDD4-1 is expressed in pituitary adenomas or whether its expression is associated with their invasiveness or with PTEN. In the present study, the expression of NEDD4-1 and PTEN in invasive and non-invasive pituitary adenomas and normal pituitary tissues were analyzed using immunohistochemistry, and their correlation was assessed. The present study aimed to investigate the possible molecular mechanisms of the genesis and invasiveness of pituitary adenomas, and to identify biomarkers for early detection as well as characterization of the biological behavior of pituitary adenomas.

\section{Materials and methods}

Patients and reagents. The specimens for immunohistochemical analysis were collected from 50 patients with pituitary adenomas who underwent treatment at the Department of Neurosurgery of Heze Municipal Hospital (Heze, China) from July 2012 to May 2015. The patient cohort comprised 27 males and 23 females, with a male-to-female ratio of 1.17:1. The average age of the patients was 38.7 years (range, 18-78 years). According to the presence or absence of invasion of the tumors to the surrounding bones and cavernous sinus, patients were divided into the invasive group (26 cases) and the non-invasive group (24 cases) (Table I). Furthermore, 10 samples of normal pituitary tissues were obtained through normal autopsy. Rabbit anti-human NEDD4-1 polyclonal antibody (cat. no. bs-3506R-AF350; 1:200 dilution) and rabbit anti-human PTEN polyclonal antibody (cat. no. DM-0748R,1:300 dilution) were from Santa Cruz Biotechnology, Inc. (Dallas, TX, USA), and secondary antibodies were from a designated immunohistochemistry 
kit for rabbit antibodies (Beijing Zhongshan Golden Bridge Biotechnology Co., Ltd., China). All experiments and use of the specimens in the present study were approved by the Ethics Committee of Heze Municipal Hospital (Heze, China), and all patients provided written informed consent prior to enrollment.

Immunohistochemical staining procedures. Paraffin-embedded specimens were cut into $4-\mu \mathrm{m}$ thick sections, which were deparaffinized in turpentine, rehydrated in an ascending ethanol series and incubated in citrate buffer $(0.01 \mathrm{~mol} / \mathrm{l}, \mathrm{pH} 6.0)$ with water bath heating $\left(\sim 98^{\circ} \mathrm{C}\right)$ for $15 \mathrm{~min}$ for antigen recovery. Following a general streptavidin-biotin complex immunohistochemical protocol (9), immunoreactivity was visualized with diaminobenzidine and the nuclei were counterstained with hematoxylin. Sections were then subsequently dehydrated in a series of graded alcohols, cleared in xylene and mounted. Prostate cancer samples were used as the positive control and slides incubated with phosphate-buffered saline without antibody were used as the negative control.

Evaluation of immunohistochemical staining. For each sample, 10 microscopic fields (magnification, x200) were selected from the tissue sections with the strongest immune response. A total of 100 cells per field were counted and averaged. The percentage of positively stained cells was recorded. Staining was rated according to the color intensity and the percentage of positive cells. Positive staining was defined as the staining intensity being markedly higher than that of the background. Staining was classified into four categories according to the number of stained cells and the staining intensity: Negative [- (i.e., the staining intensity was not significantly different from the background)]; weakly positive [+ (i.e., the percentage of positively stained cells was $<10 \%$, or the staining intensity was weakly positive or only individual cells were positive to strongly positive)]; moderately positive [++ (i.e., the percentage of positive cells was $10-60 \%$ )]; strongly positive [+++ (i.e., the percentage of positively stained cells was $>60 \%$, or the staining intensity was moderately to strongly positive and only a few cells were weakly positive]. The known positive prostate section was selected as the positive control.

Statistical analysis. SPSS 18.0 software was used for statistical analysis. The two-samples t-test and analysis of variance were used to assess differences between groups. The $\chi^{2}$ test and exact test on a four-fold table were used to determine differences in the positive staining rate between normal pituitary tissues and invasive, as well as non-invasive, pituitary adenomas. The Line $x$ List $\chi^{2}$ test and the one-sided test were used for correlation analyses. $\alpha=0.05$ was considered as the level of significance. $\mathrm{P}<0.05$ was considered to indicate a statistically significant difference.

\section{Results}

NEDD4-1 expression in pituitary tissues/adenoma increases with the degree of malignancy. Immunohistochemistry revealed that NEDD4-1 was expressed in the cytoplasm
Table I. Clinical data of patients with pituitary adenoma.

\begin{tabular}{lcc}
\hline Characteristic & $\begin{array}{c}\text { Invasive } \\
\text { group (n) }\end{array}$ & $\begin{array}{c}\text { Non-invasive } \\
\text { group (n) }\end{array}$ \\
\hline Cases & 26 & 24 \\
Age (years) & 20 & 15 \\
$\geq 40$ & 6 & 9 \\
$<40$ & 13 & \\
Gender & 13 & 14 \\
Male & & 10 \\
Female & 2 & 5 \\
Endocrine type & 6 & 3 \\
ACTH & 8 & 10 \\
GH & 10 & 6 \\
PRL & & 6 \\
Others & 21 & 18 \\
Operative method & 5 & \\
Transcranial & & \\
Trans-sphenoidal & &
\end{tabular}

ACTH, adrenocorticotropic hormone; GH, growth hormone; PRL, prolactin.

and/or the nucleus (Fig. 1). The positive rate of NEDD4-1 expression in the normal control group [10.0\% (1/10)] was significantly lower compared with that in the experimental group [52.0\% (26/50); $\mathrm{P}<0.05]$ (Table II). The positive rate of NEDD4-1 was $37.5 \%(9 / 24)$ in the non-invasive pituitary adenomas group and $65.3 \%(17 / 26)$ in the invasive adenomas group, thereby revealing a significantly increasing trend with the increasing degree of tumor invasiveness $(\mathrm{P}<0.05)$; the differences were also significant compared with the control group $(\mathrm{P}<0.05)$.

PTEN protein expression in pituitary tissues/adenoma decreases with increasing degree of malignancy. Immunohistochemistry revealed that PTEN was mainly expressed in the cytoplasm, displaying as a brownish-yellow stain (Fig. 2). The rate of PTEN expression in the normal control group $[100.0 \%(10 / 10)]$ was significantly higher compared with that in the experimental group [54.0\% (27/50); P<0.05] (Table III). The positive rate of PTEN was $83.3 \%$ (20/24) in the non-invasive pituitary adenoma group and $26.9 \%$ (7/26) in the invasive pituitary adenoma group, thereby revealing a significantly decreasing trend with the increasing degree of tumor invasiveness $(\mathrm{P}<0.05)$; the differences were also significant compared with the control group $(\mathrm{P}<0.05)$.

Inverse correlation of NEDD4-1 and PTEN protein expression in pituitary adenomas. Among the 26 cases of pituitary adenomas which stained positive for NEDD4-1, four were positive for PTEN. Furthermore, among the 27 cases of pituitary adenomas which stained positive for PTEN, 24 were negative for NEDD4-1. Statistical analysis revealed a negative correlation between the two proteins $(\gamma=-0.711, \mathrm{P}<0.05)$ (Table IV). 


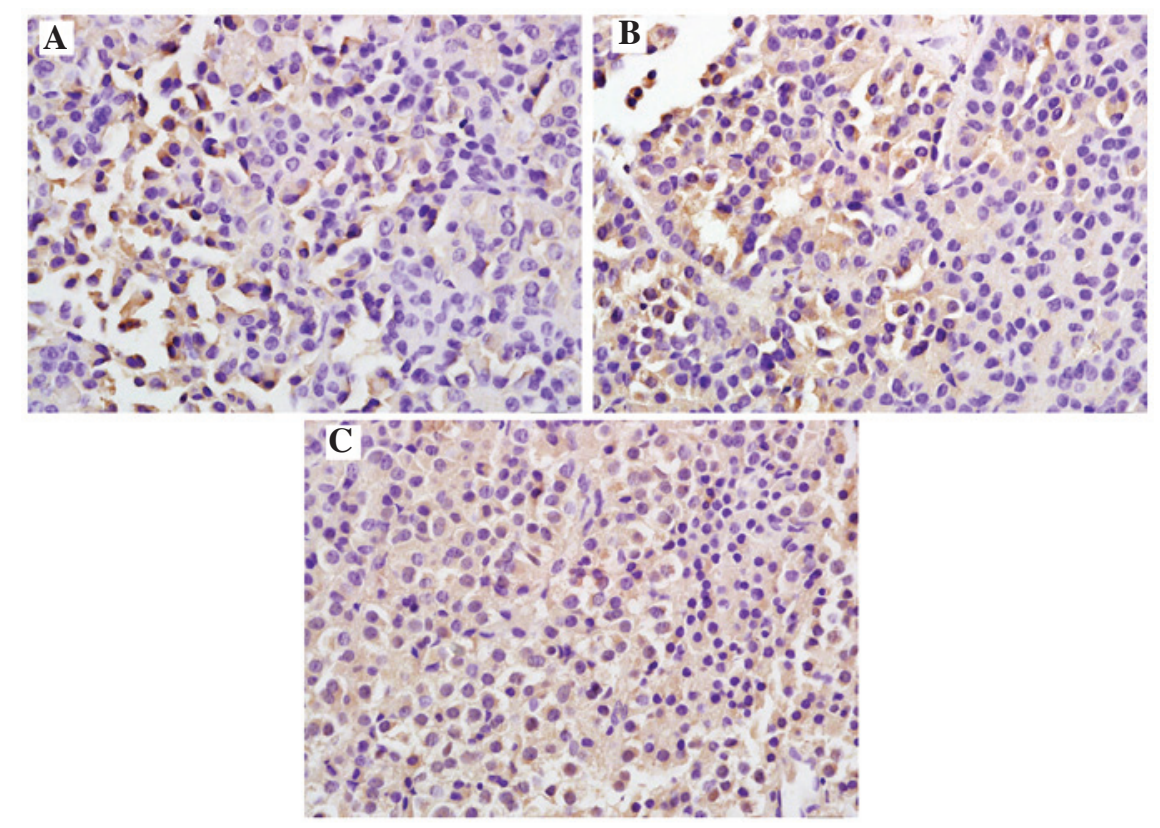

Figure 1. NEDD4-1 expression in normal pituitary tissue and pituitary adenomas (magnification, x200). NEDD4-1 was expressed in the cytoplasm and/or the nucleus. The expression of NEDD4-1 in (A) normal pituitary tissues was lower compared with that in (B) the non-invasive group (P<0.05), which was in turn lower compared with that in (C) the invasive group. NEDD4-1 expression therefore increased with the degree of tumor invasiveness. NEDD4-1, neural precursor cell expressed developmentally downregulated 4-1.

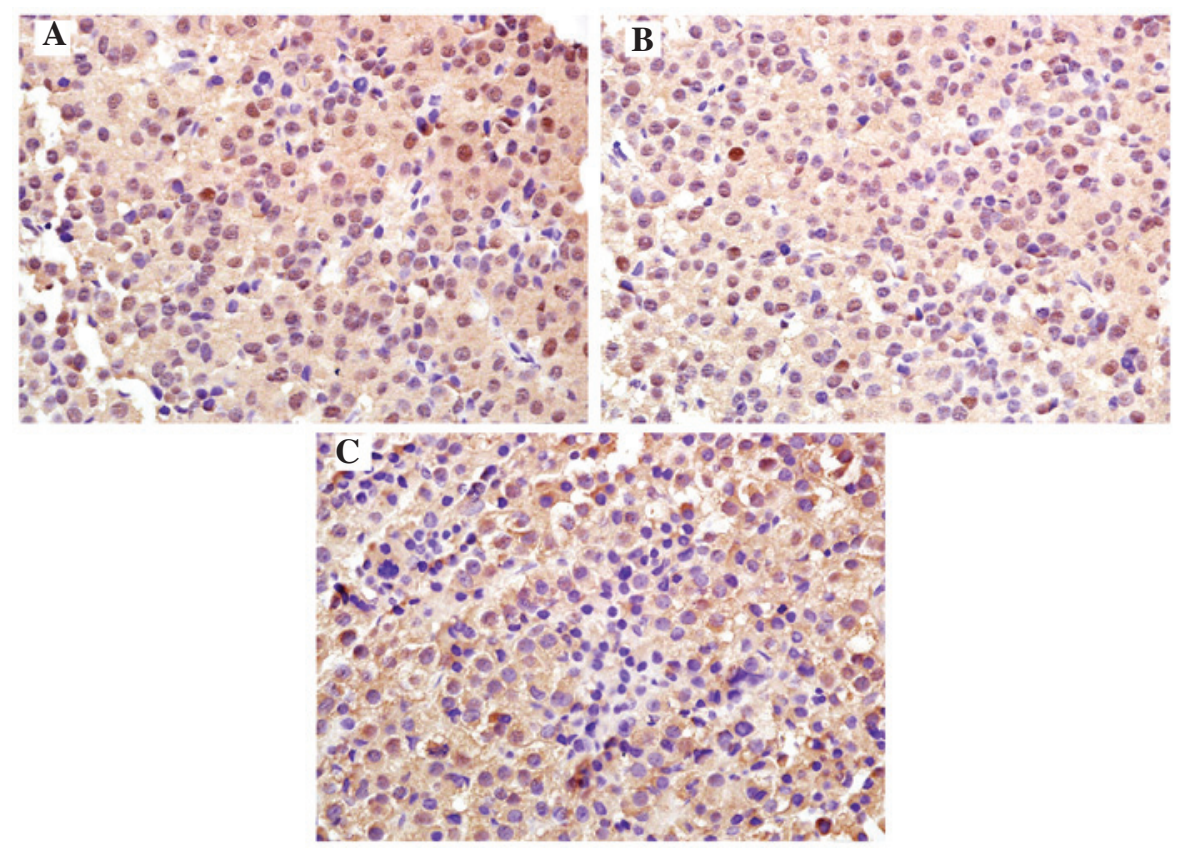

Figure 2. PTEN expression in normal pituitary tissue and pituitary adenomas (magnification, $\mathrm{x} 200$ ). PTEN was mainly expressed in the cytoplasm, displaying as a brownish-yellow stain. The expression of PTEN in (A) normal pituitary tissues was higher compared with that in (B) the non-invasive group (P<0.05), which was in turn higher compared with that in $(\mathrm{C})$ the invasive group. The positive rate had a significantly decreasing trend with the increasing degree of tumor invasiveness. PTEN, phosphatase and tensin homolog deleted on chromosome 10.

\section{Discussion}

In general, the growth of pituitary adenomas is limited; however, in certain cases, they may invade the surrounding brain tissues, blood vessels and nerves, and destroy the sellar bone, thereby showing characteristics of malignant tumors that require complete surgical resection (10-12). According to the concepts of modern molecular biology of tumors, the occurrence and development of tumors constitutes a multi-factorial, multi-step and complex biological evolutionary process involving the mutation of multiple genes, and pituitary adenoma is no exception (13-15). PTEN is among the tumor suppressor genes with the highest vulnerability to mutations $(16,17)$. NEDD4-1 is a newly discovered ubiquitin ligase of PTEN, with HECT (homologous to the E6-AP carboxyl terminus) domains. NEDD4-1 has a role in the multi-ubiquitination of PTEN 
Table II. Protein expression of neural precursor cell expressed developmentally downregulated 4-1 in normal pituitary tissues and in pituitary adenoma (invasive and non-invasive).

\begin{tabular}{|c|c|c|c|c|c|c|c|}
\hline \multirow[b]{2}{*}{ Group } & \multirow[b]{2}{*}{ Cases (n) } & \multirow[b]{2}{*}{ Negative (n) } & \multicolumn{3}{|c|}{ Positive (n) } & \multirow[b]{2}{*}{ Total positives (n) } & \multirow[b]{2}{*}{ Positive rate $(\%)$} \\
\hline & & & + & ++ & +++ & & \\
\hline Normal & 10 & 9 & 1 & 0 & 0 & 1 & 10.0 \\
\hline Non-invasive & 24 & 15 & 5 & 4 & 0 & 9 & $37.5^{\mathrm{a}}$ \\
\hline Invasive & 26 & 9 & 4 & 6 & 7 & 17 & $65.3^{\mathrm{b}}$ \\
\hline
\end{tabular}

${ }^{a} \mathrm{P}<0.05$ compared with the normal group, ${ }^{\mathrm{b}} \mathrm{P}<0.05$ compared with the non-invasive group.

Table III. Protein expression of phosphatase and tensin homolog deleted on chromosome 10 in normal pituitary tissues and in pituitary adenoma (invasive and non-invasive).

\begin{tabular}{|c|c|c|c|c|c|c|c|}
\hline \multirow[b]{2}{*}{ Group } & \multirow[b]{2}{*}{ Cases (n) } & \multirow[b]{2}{*}{ Negative (n) } & \multicolumn{3}{|c|}{ Positive (n) } & \multirow[b]{2}{*}{ Total positives (n) } & \multirow[b]{2}{*}{ Positive rate $(\%)$} \\
\hline & & & + & ++ & +++ & & \\
\hline Normal & 10 & 0 & 2 & 3 & 5 & 10 & 100.0 \\
\hline Non-invasive & 24 & 4 & 5 & 5 & 10 & 20 & $83.3^{\mathrm{a}}$ \\
\hline Invasive & 26 & 19 & 4 & 2 & 1 & 7 & $26.9^{b}$ \\
\hline
\end{tabular}

${ }^{\mathrm{a}} \mathrm{P}<0.05$ compared with the normal group, ${ }^{\mathrm{b}} \mathrm{P}<0.05$ compared with the non-invasive group.

and degradation of its proteasome $(4,18,19)$. In the present study, the expression of PTEN and NEDD4-1 in invasive and non-invasive pituitary adenomas and normal pituitary tissues was explored using immunohistochemistry and their correlation was analyzed.

Although the genetic status of PTEN was not evaluated in the present study, it is likely that inactivation of PTEN may have led to the loss of protein expression detected by immunohistochemistry. Of note, the loss of PTEN protein expression is an important negative prognostic indicator (20-22). Immunohistochemical analysis may be the best method for evaluating the PTEN status, as it is able to detect PTEN loss due to various causes, including the inactivation of the gene product (23-25). By using immunohistochemistry, the present study revealed that the rate of PTEN-positive cells was significantly different between patients with non-invasive pituitary adenomas $[83.3 \%(20 / 24)]$ and those with invasive pituitary adenomas [26.9\% (7/26); $\mathrm{P}<0.05]$, whereas $100 \%$ of cells in normal pituitary tissues were PTEN-positive. This result indicated that the expression intensity of PTEN was reduced with the increase in the degree of tumor invasiveness. It can be speculated that deletion of the PTEN gene is one of the reasons of decreased protein levels in pituitary adenomas compared with normal pituitary tissues.

The positive rate of NEDD4-1 expression in normal pituitary tissues was $10.0 \%$, which was significantly lower compared with that in pituitary adenomas (52.0\%; $\mathrm{P}<0.05)$. Furthermore, the NEDD4-1-positive rate in the non-invasive pituitary adenoma group $(37.5 \%)$ was significantly lower compared with that in the invasive group $(65.3 \%$; $<<0.05)$, indicating that NEDD4-1 may be associated with the degree
Table IV. Correlation of NEDD4-1 and PTEN expression in pituitary adenomas.

\begin{tabular}{lccc}
\hline & \multicolumn{2}{c}{ PTEN } & \\
\cline { 2 - 3 } NEDD4-1 & Positive (n) & Negative (n) & Total (n) \\
\hline Positive & 4 & 22 & 26 \\
Negative & 23 & 1 & 24 \\
Total & 27 & 23 & 50 \\
\hline
\end{tabular}

$\chi^{2}=30.347 ; \quad \mathrm{P}<0.05 ; \quad$ correlation coefficient $\gamma=-0.711 ; \quad \alpha=0.05$. NEDD4-1, neural precursor cell expressed developmentally downregulated 4-1; PTEN, phosphatase and tensin homolog deleted on chromosome 10.

of malignancy or loss of histological differentiation. It was speculated that, with an increasing degree of malignancy, NEDD4-1 protein participated in PTEN protein degradation by polyubiquitylation, thus resulting in increased NEDD4-1 protein expression. Therefore, the overexpression of NEDD4-1 is likely to have an important role in the development of pituitary adenoma.

To the best of our knowledge, the present study was the first to assess NEDD4-1 and PTEN expression in pituitary adenoma. Among 26 cases of NEDD4-1-positive pituitary adenoma, four were PTEN-positive, whereas, among 27 cases of PTEN-positive pituitary adenoma, 24 were NEDD4-1-negative. Statistical analysis revealed a negative correlation between NEDD4-1 and PTEN $(\gamma=-0.711 ; \mathrm{P}<0.05)$. 
With the increasing degree of invasiveness of pituitary adenoma, the NEDD4-1-positive rate was increased, whereas the PTEN-positive rate was decreased. A possible underlying mechanism is that increased expression of NEDD4-1 leads to an increase in PTEN ubiquitination, thus causing its degradation in the proteasome.

In conclusion, the present study showed that NEDD4-1 and PTEN may have an important role in the occurrence and development of pituitary adenoma, which was associated with the degree of invasiveness and prognosis of pituitary adenoma. The two proteins may thus be utilized as diagnostic and prognostic biomarkers, as well as indicators for determining the biological characteristics of pituitary adenoma. However, the specific mechanisms of the roles of NEDD4-1 and PTEN in pituitary adenomas remain to be fully elucidated by further experimental studies.

\section{References}

1. Palumbo T, Faucz FR, Azevedo M, Xekouki P, Iliopoulos D and Stratakis CA: Functional screen analysis reveals miR-26b and miR-128 as central regulators of pituitary somatomammotrophic tumor growth through activation of the PTEN-AKT pathway. Oncogene 32: 1651-1659, 2013

2. Li DM and Sun H: TEP1, encoded by a candidate tumor suppressor locus, is a novel protein tyrosine phosphatase regulated by transforming growth factor- $\beta$. Cancer Res 57: 2124-2129, 1997.

3. Li J, Yen C, Liaw D, Podsypanina K, Bose S, Wang SI, Puc J, Miliaresis C, Rodgers L, McCombie R, et al: PTEN, a putative protein tyrosine phosphatase gene mutated in human brain, breast, and prostate cancer. Science 275: 1943-1947, 1997.

4. Wang X, Trotman LC, Koppie T, Alimonti A, Chen Z, Gao Z, Wang J, Erdjument-Bromage $\mathrm{H}$, Tempst $\mathrm{P}$, Cordon-Cardo C, et al NEDD4-1 is a proto-oncogenic ubiquitin ligase for PTEN. Cell 128: 129-139, 2007.

5. Wu DN, Pei DS, Wang Q and Zhang GY: Down-regulation of PTEN by sodium orthovanadate inhibits ASK1 activation via PI3-K/AKT during cerebral ischemia in rat hippocampus. Neurosci Lett 404: 98-102, 2006.

6. Castellino RC and Durden DL: Mechanisms of disease: The PI3K-AKT-PTEN signaling node - an intercept point for the control of angiogenesis in brain tumors. Nat Clin Pract Neurol 3 : 682-693, 2007

7. Tena-Suck ML, Ortiz-Plata A and de la Vega HA: Phosphatase and tensin homologue and pituitary tumor-transforming gene in pituitary adenomas. Clinical-pathologic and immunohistochemical analysis. Ann Diagn Pathol 12: 275-282, 2008.

8. Feng ZZ, Chen JW, Yang ZR, Lu GZ and Cai ZG: Expression of PTTG1 and PTEN in endometrial carcinoma: Correlation with tumorigenesis and progression. Med Oncol 29: 304-310, 2012.

9. Li X, Li M, Tian X, Li Q, Lu Q, Jia Q, Zhang L, Yan J, Li X and Li X: Golgi phosphoprotein 3 inhibits the apoptosis of human glioma cells in part by downregulating N-myc downstream regulated gene 1. Med Sci Monit 22: 3535-3543, 2016.
10. Vivanco I and Sawyers CL: The phosphatidylinositol 3-kinase AKT pathway in human cancer. Nat Rev Cancer 2: 489-501, 2002.

11. Whiteman DC, Zhou XP, Cummings MC, Pavey S, Hayward NK and Eng C: Nuclear PTEN expression and clinicopathologic features in a population-based series of primary cutaneous melanoma. Int J Cancer 99: 63-67, 2002.

12. Faisal Ahmed S, Marsh DJ, Weremowicz S, Morton CC, Williams DM and Eng C: Balanced translocation of 10q and 13q, including the PTEN gene, in a boy with a human chorionic gonadotropin-secreting tumor and the Bannayan-Riley-Ruvalcaba syndrome. J Clin Endocrinol Metab 84: 4665-4670, 1999.

13. Wu LM, Li YL, Yin YH, Hou GQ, Zhu R, Hua XL, Xu JR and Chen ZA: Usefulness of dual-energy computed tomography imaging in the differential diagnosis of sellar meningiomas and pituitary adenomas: Preliminary report. PLoS One 9: e90658, 2014

14. Cao XR, Lill NL, Boase N, Shi PP, Croucher DR, Shan H, Qu J, Sweezer EM, Place T, Kirby PA, et al: Nedd4 controls animal growth by regulating IGF-1 signaling. Sci Signal 1, ra5, 2008.

15. Treier M, Staszewski LM and Bohmann D: Ubiquitin-dependent c-Jun degradation in vivo is mediated by the delta domain. Cell 78: 787-798, 1994.

16. Chou TC: Theoretical basis, experimental design, and computerized simulation of synergism and antagonism in drug combination studies. Pharmacol Rev 58: 621-681, 2006.

17. Franke TF, Kaplan DR, Cantley LC and Toker A: Direct regulation of the Akt proto-oncogene product by phosphatidylinositol 3,4-bisphosphate. Science 275: 665-668, 1997.

18. Wang L, Balas B, Christ-Roberts CY, Kim RY, Ramos FJ, Kikani CK, Li C, Deng C, Reyna S, Musi N, et al: Peripheral disruption of the Grb10 gene enhances insulin signaling and sensitivity in vivo. Mol Cell Biol 27: 6497-6505, 2007.

19. Yim EK, Peng G, Dai H, Hu R, Li K, Lu Y, Mills GB, Meric-Bernstam F, Hennessy BT, Craven RJ and Lin SY: Rak functions as a tumor suppressor by regulating PTEN protein stability and function. Cancer Cell 15: 304-314, 2009.

20. Drinjakovic J, Jung H, Campbell DS, Strochlic L, Dwivedy A and Holt CE: E3 ligase Nedd4 promotes axon branching by down-regulating PTEN. Neuron 65: 341-357, 2010.

21. Trotman LC, Wang X, Alimonti A, Chen Z, Teruya-Feldstein J, Yang H, Pavletich NP, Carver BS, Cordon-Cardo C, Erdjument-Bromage $\mathrm{H}$, et al: Ubiquitination regulates PTEN nuclear import and tumor suppression. Cell 128, 141-156, 2007.

22. Maccario H, Perera NM, Gray A, Downes CP and Leslie NR: Ubiquitination of PTEN (phosphatase and tensin homolog) inhibits phosphatase activity and is enhanced by membrane targeting and hyperosmotic stress. J Biol Chem 285: 12620-12628, 2010.

23. Wang X, Shi Y, Wang J, Huang G and Jiang X: Crucial role of the C-terminus of PTEN in antagonizing NEDD4-1-mediated PTEN ubiquitination and degradation. Biochem J 414: 221-229, 2008.

24. Lee JR, Oestreich AJ, Payne JA, Gunawan MS, Norgan AP and Katzmann DJ: The HECT domain of the ubiquitin ligase Rsp5 contributes to substrate recognition. J Biol Chem 284: 32126-32137, 2009.

25. Kim RH, Peters M, Jang Y, Shi W, Pintilie M, Fletcher GC, DeLuca C, Liepa J, Zhou L, Snow B, et al: DJ-1, a novel regulator of the tumor suppressor PTEN. Cancer Cell 7: 263-273, 2005. 